\title{
Overhead Pedestrian Crossings - Economic Evaluation through Vehicle Operating Cost and Travel Time Savings
}

\author{
K. M. G. N. S. Kumara, V. K. M. Pinnagoda and K. S. \\ Weerasekera * \\ Department of Civil Engineering, The Open University of Sri \\ Lanka
}

\section{Abstract:}

At-grade road crossing facility presently available at the main entrance to the Sri Lanka Institute of Information Technology (SLIIT) Malabe can be improved as a solution to minimize the disturbance of traffic flow along Malabe - Kaduwela road. It is observed that a large number of students cross the road throughout the day, especially during the peak of traffic. Several other reasons for this traffic congestion were identified, such as; unruliness of pedestrians, violation of traffic rules by drivers (especially bus drivers who stop buses everywhere although there are properly located bus stops), inadequate road width etc. Due to the above reasons, vehicles traveling along this stretch of road have to constantly slow down and then regain their original speed after passing the location. Introduction of an overhead pedestrians' crossing at the location would separate pedestrians from traffic to minimize the vehicle - pedestrian conflict to create a uniform traffic flow along the road section. Hence, by minimizing the sudden speed variation of vehicles (speed change cycle) due to the existing pedestrians crossing the road, the additional Vehicle Operating Cost (VOC), additional travel time and risk for pedestrians when crossing the road, as well as uncomfortable driving condition for drivers can be reduced.

The objective of this study is to minimize the additional VOC and travel time due to sudden speed variation at this existing pedestrian crossing by improving the traffic flow condition. Therefore, an overhead pedestrian crossing with the view of facilitating the pedestrians to cross the road comfortably and safely is proposed. The proposed structure has a clear height of $5.5 \mathrm{~m}$ and $18 \mathrm{~m}$ of span. Two flights of steps of one meter width were designed for both ends of the overhead bridge as access.

* Correspondence should be addressed to Professor K. S. Weerasekera, Dept. of Civil Engineering, Faculty of Engineering Technology, The Open University of Sri Lanka (email: kolitaw@gmail.com) 
Total cost for the proposed structure was computed for the year of 2012. Further the additional cost for the VOC and travel time per day were analyzed and predicted for a period of 20 years from the year 2012. After having determined the costs and benefits of the project, a method was evolved for relating these two so as to arrive at the assessment of the viability of the project in economic terms. Among a number of methods developed for such an economic evaluation, Internal Rate of Return (IRR) method was justified and selected.

Keywords: Overhead Pedestrian Crossings, Vehicle Operating Costs, Speed Change Cycles

\section{Introduction}

When a vehicle travels at its cruise speed, if the speed is interrupted due to change of road geometry, road features or any road event (such as lane reductions, presence of road intersections, interruptions due to pedestrian crossings etc.), it decelerates to a minimum speed (which can be even a complete stop). Subsequently, the vehicle has to accelerate back to its original cruise speed. A vehicle undergoes a speed change cycle which is the difference in travel time and Vehicle Operating Cost (VOC) for traveling the distance of the speed cycle at the original cruise speed versus reduction of speed through the speed cycle.

The Malabe - Kaduwela road with an Average Daily Traffic (ADT) of 39,800 vehicles per day in front of Malabe Campus of the Sri Lanka Institute of Information Technology (SLIIT) was selected as the study location.

At this location, traffic flow is constantly obstructed by the existing pedestrian crossing at the entrance of the Malabe Campus of SLIIT. This stretch of road is straight with minimum disturbance to traffic except for heavy pedestrian crossing taking place at the location. Because of this very high ADT, of 39,800 reductions and regaining the speed of vehicles cause additional VOC, increase travel time, higher accident risk, increase in vehicular emissions, and additional cost to the national economy may result. 


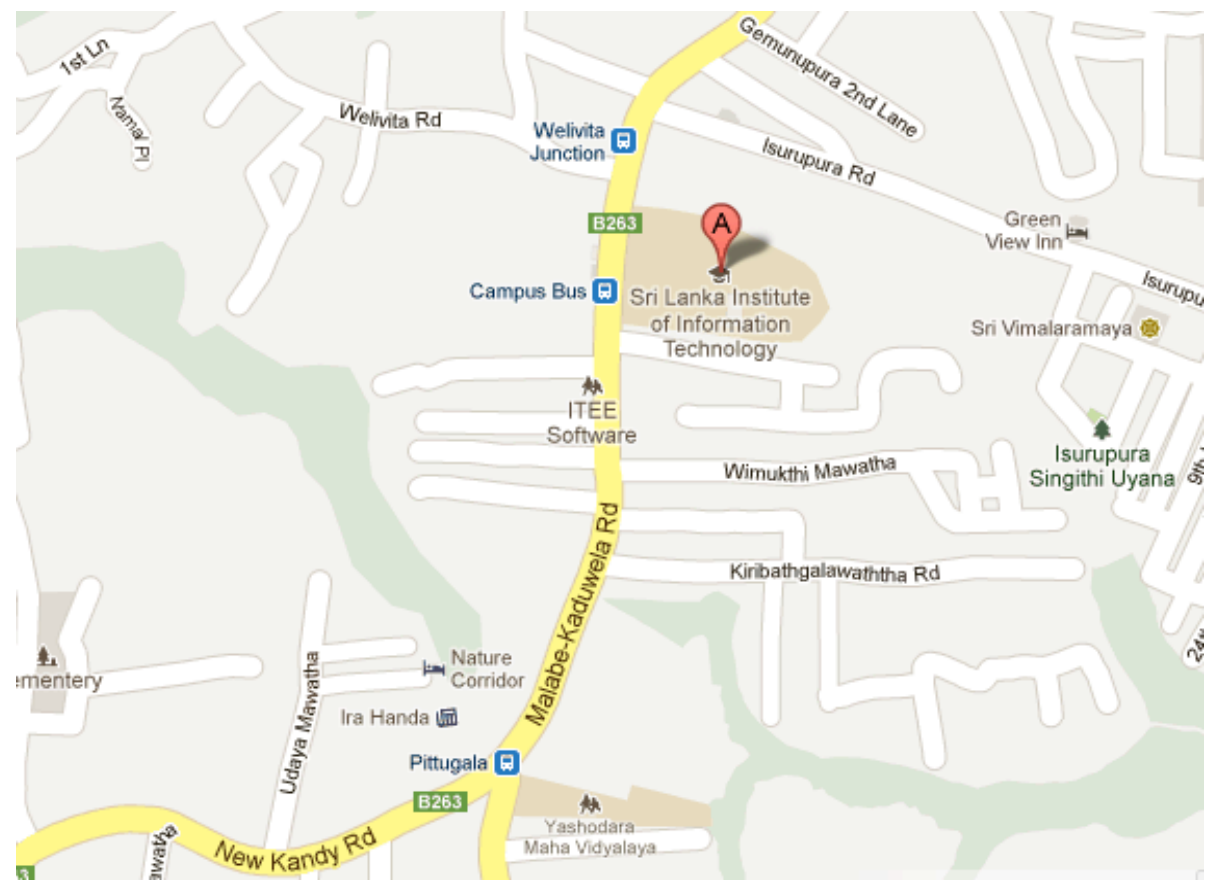

Figure 1. Location of the study

Hence, one can quantify the additional cost for more fuel and oil consumption, wastage of tires, wear and tear of mechanical parts, additional travel time etc. As a solution, to separate the pedestrian and vehicular movement, a safe overhead pedestrian crossing structure is proposed. The construction cost is compared with the savings from reduction in travel time and $\mathrm{VOC}$, and then construction of the structure is justified by carrying out a cost/benefit analysis.

\section{Aim and Objectives}

The aim of this project is to quantify the value of additional burden to economy due to the speed change of a vehicle at the existing crossing; predict it for future time periods. This also attempts to reveal how long it will take to recover the construction cost if an overhead crossing is introduced to the main entrance of SLIIT, instead of the existing ground level crossing. To achieve the above aim, the following objectives 
had to be achieved. This study will justify and design an overhead pedestrian crossing at the main entrance to SLIIT, for reduced speed variation of traffic and safe movement of vehicular and pedestrian traffic by paying attention to the following:

- Quantify the additional vehicle operating cost and additional travel time and predict it for the future time periods.

- Forecast the number of pedestrians, crossing at the location after 20 years.

- Estimate the construction cost of the overhead pedestrian crossing and compare it with the saving on additional burden on economy to calculate the recovery period of construction cost.

In addition to the above objectives, there are some interim objectives that should be satisfied.

1. To check whether the road capacity of Malabe - Kaduwela road is adequate to cater to the current traffic volume.

2. Design the Malabe - Kaduwela road for year 2032 with a suitable level of service to cater to forecasted traffic volume.

3. Design of overhead pedestrian crossing to suit the pedestrian activities in this area and with an acceptable level of service to cater to forecasted pedestrian volume for year 2032 .

\section{Methodology}

Step 1: Traffic survey

Firstly, traffic flow pattern and pedestrian crossing pattern around the study area were measured. Vehicles were counted manually on both directions at 15-minute intervals on a week day. Two directional vehicular flows for 24 hours are as shown in Figure 2. Peak hours were identified as; morning peak is $7: 00$ to $8: 00$ a.m., mid-day peak is $1: 00$ to 2:00 p.m. and evening peak is 5:00 to $6: 00$ p.m. 


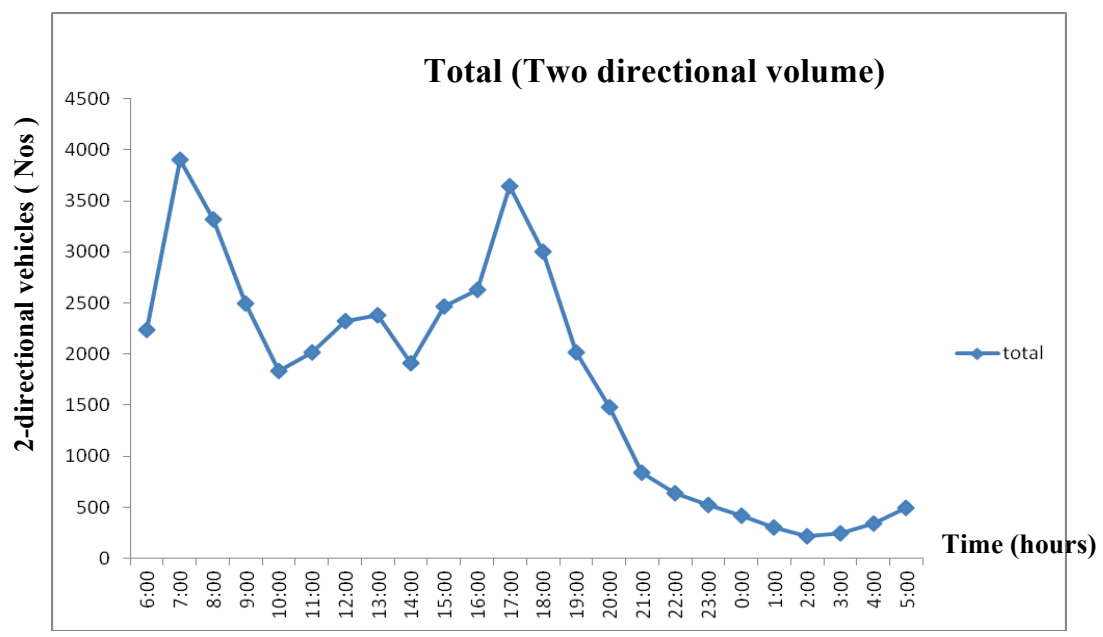

Figure 2. 24 hour vehicle distribution

Step 2: Pedestrian survey

A pedestrian count at the entrance to the SLIIT was done for 5-minute intervals throughout the day, in order to identify the pedestrian peak hours. Two directional pedestrian crossing flows is as shown in Figure 3. Pedestrian crossing peaks were identified as; morning peak from $7: 45$ to $8: 45$ a.m., mid-day peak from $12: 45$ to $1: 45$ p.m. and evening peak from 4:55 to 5:55 p.m. on a week day. 


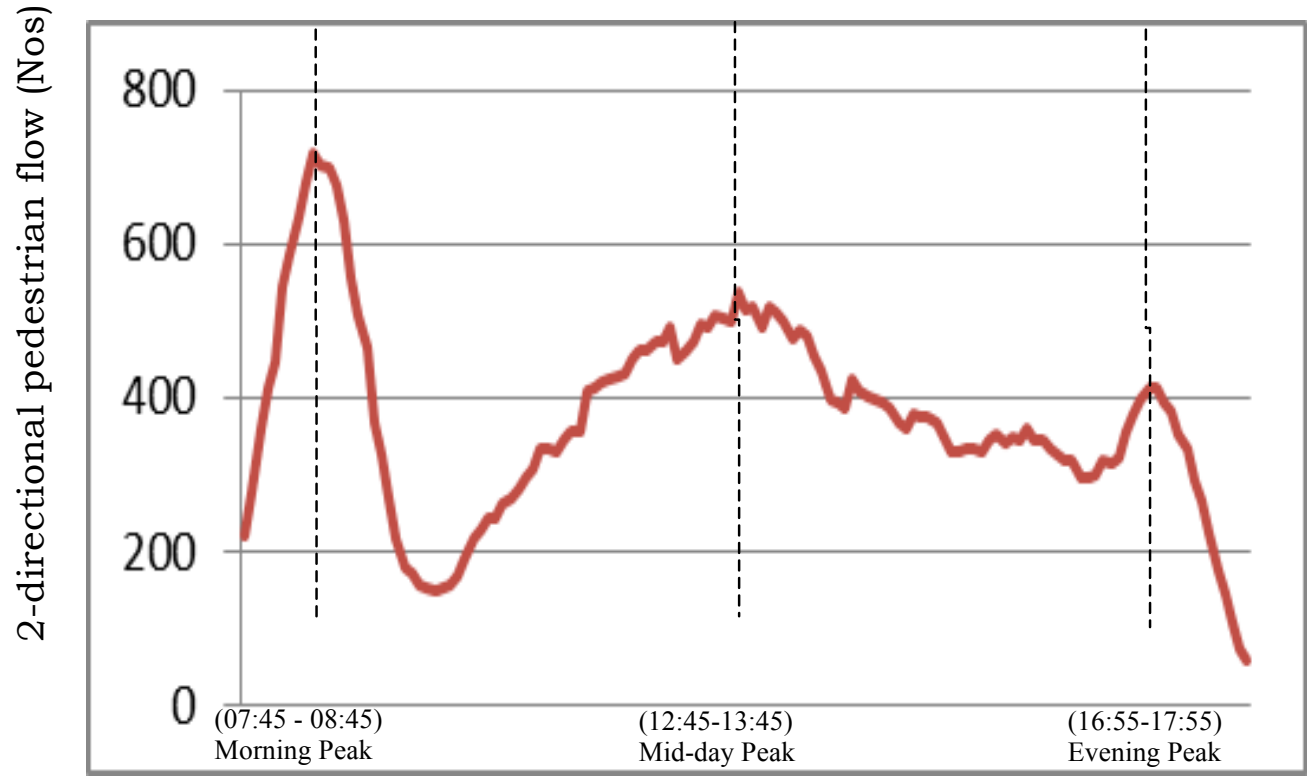

Time (hours)

Figure 3. Two directional pedestrian crossing flow

Step 3: Traffic volume study

As per two directional traffic volume, 7 time slots were selected to carry out the speed profile study as indicated in Figure 4. The study analysis was carried-out under following assumptions. It was assumed that vehicular flow pattern and vehicle composition at the study location is the same all 7 days through the year. It was also assumed that flow pattern changes due to weather changes and the peak hours will not vary. Seasonal variation of traffic at the study location has been ignored.

To generate average speed profiles the time slots were taken as follows (Figure 4):

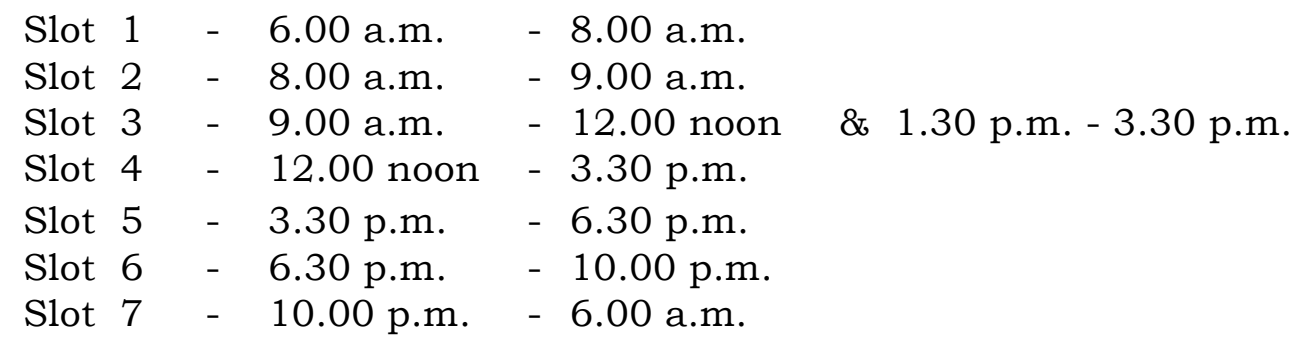




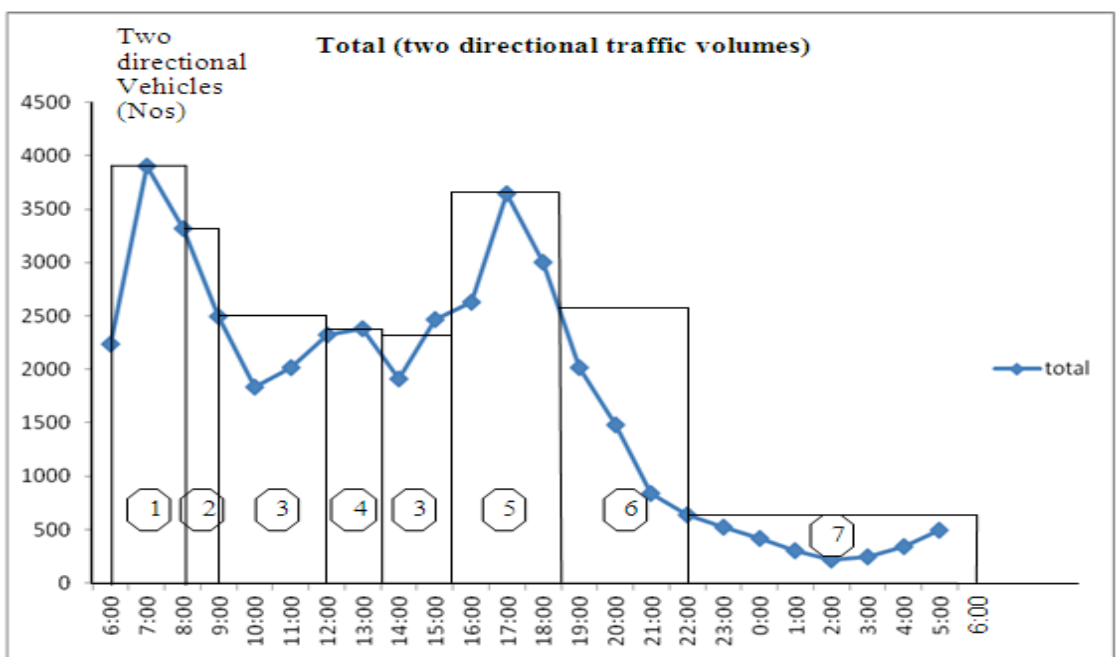

Time (Hours)

Figure 4. Two directional traffic volumes and different time slots

Step 4: Speed measurements

As shown in Figure 5, either sides of the existing pedestrian crossing were divided into $10 \mathrm{~m}$ sections to take speed measurements. Speeds of random 25 vehicles (including all vehicle categories) were measured in every 10 meter road segment. In addition, average speed was measured 100 meters away from the pedestrian crossing along both sides. Average speed variation for all categories of vehicles during each time slot (for both directions) was recorded and corresponding speed profiles for each time were drawn.

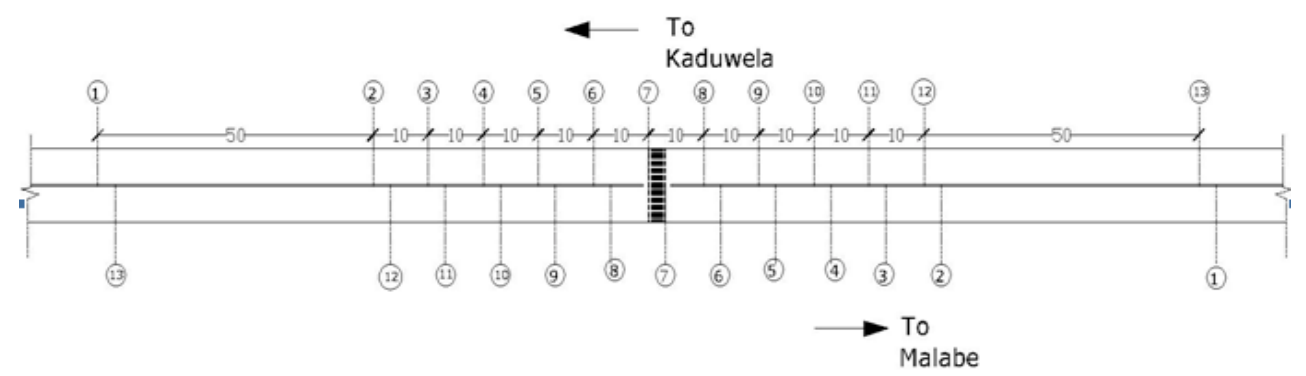

Figure 5. Speed measurement locations 


\section{Speed Profiles}

Table 1 and Figure 6 indicate the average speed profile for time slot 1 (i.e. 6.00 a.m. - 8.00 a.m. from Malabe to Kaduwela direction). Similarly, average speed profiles of both travel directions for all 7 time slots were plotted.

Table 1. Speed variation of traffic during morning peak hour

\begin{tabular}{|l|c|c|c|c|c|c|c|c|c|c|c|c|c|}
\hline \multicolumn{10}{|c|}{ Speed Variation in 06:00 - 08:00 } \\
\hline Section & 1 & 2 & 3 & 4 & 5 & 6 & 7 & 8 & 9 & 10 & 11 & 12 & 13 \\
\hline Distance & -100 & -50 & -40 & -30 & -20 & -10 & 0 & +10 & +20 & +30 & +40 & +50 & +100 \\
\hline Speed & 47 & 47 & 46 & 33 & 29 & 21 & 13 & 21 & 26 & 29 & 37 & 47 & 47 \\
\hline
\end{tabular}

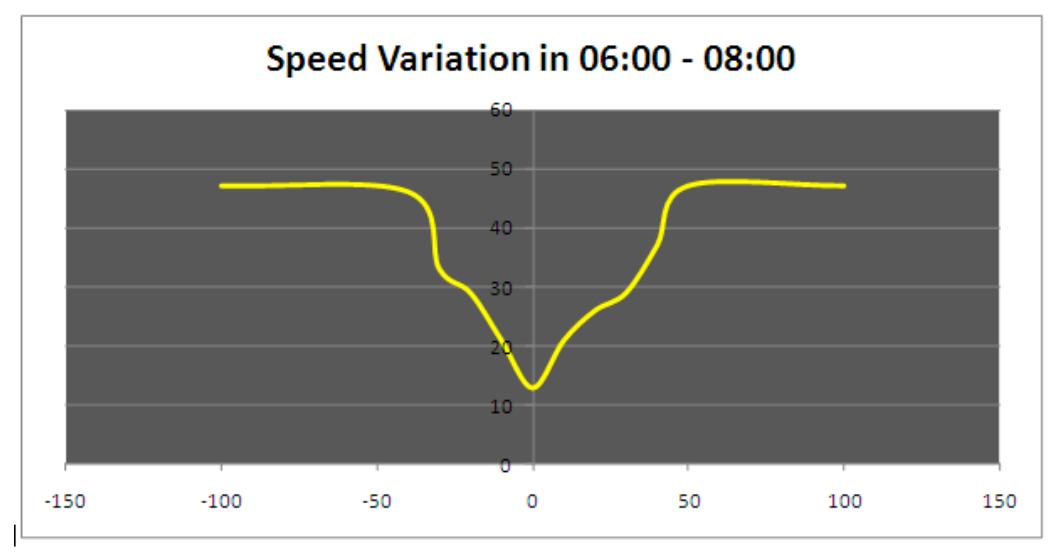

Figure 6. Average speed profile for time slot 1 (6.00 a.m. - 8.00 a.m. from Malabe to Kaduwela)

Step 5: Determination of additional vehicle operating cost (VOC) and additional travel time for a speed change cycle

The additional vehicle operating cost for speed change cycles of each vehicle category was computed by using the VOC tables obtained from NZ Transport Agency's Economic Evaluation. Within the selected time slots additional VOC for each vehicle class was computed for both directions. Hence, 
the total additional VOC values per day (due to speed change cycle) for all classes were computed separately.

The additional travel time for a speed change cycle is the difference in travel time for traveling the distance of the speed cycle at the original cruise speed versus reduced speed through the speed cycle. The road user values are used to produce travel time values for uncongested and congested traffic conditions. Hence with the help of speed change cycles, savings on VOC and travel time were computed on annual basis due to the construction of the overhead pedestrian crossing.

Step 6: Design of the overhead pedestrian crossing

Based on the pedestrian counts and opinion survey results, the overhead pedestrian crossing structure was designed at the location for minimum pedestrian/traffic conflict. The span of the structure was decided based on the designed carriageway width of the road for a projected traffic for 20 years from present. The width of the structure was determined according to the forecasted pedestrian volume after the same period of time for a LOS of $\mathrm{C}$ (Highway Capacity Manual, 1985). Vertical clearance was decided based on RDA standards (RDA, 1998). Design of the structure was done as a combination of pre-stressed and reinforced concrete. Details of structural designs of the study are not indicated in this publication.

\section{Step 7: Cost estimation}

As described in step 5, the total additional VOC per a typical day for all vehicle classes as they undergo a speed change cycle due to the existing pedestrian crossing was computed. At the same time, for the same speed change cycle, additional travel time per day for all vehicle classes was determined (NZ Transport Agency). The total cost for additional travel time for all vehicles classes was calculated by considering the annual income of different road users. The total cost for additional travel time, the total cost for fuel and oil wastage, total cost for tire wastages, total cost for maintenance and repairs, total cost for depreciation per day were also computed. It can also be predicted for future time periods by taking in to account the traffic growth rate in 
Colombo district.

The construction cost of the overhead pedestrian crossing was computed separately.

Step 8: Economic evaluation

By comparing the various methods available for economic evaluation, Internal Rate of Return (IRR) method was selected for economic evaluation of this study. The IRR is the discount rate, which makes the discounted future benefits equal to the initial outlay. In other words, it is the discount rate, which makes the stream of cash flow to zero.

\section{Data Analysis}

\section{The traffic volume forecast}

Traffic volume forecast for future time periods is required for designing of road width and additional lanes to be provided after 20 years. Afterwards, designed road width is required to determine the effective span of the over passes. Road width and number of lanes to be provided is determined according to US highway capacity manual 1985. By considering parameters such as present traffic volume, vehicle categories, per capita income, traffic growth rate, number of by-roads, number of junction and round about etc. RDA has developed a system to predict the average number of vehicles for a typical day of a forthcoming year on each road section governed by RDA in the Colombo area. Traffic data was collected from RDA to find the traffic growth of selected road section.

\section{Pedestrians' volume forecast}

Pedestrians' volume forecast for a future time period is required for designing the width of the over pass after 20 years. According to the data of Census and Statistics Department, the average annual population growth rate of Colombo district is $1.4 \%$ (Department Census and Statistics).

\section{Additional vehicles operating cost (VOC)}

Every vehicle around the existing pedestrian crossings undergoes speed reduction and re-gaining back to the initial speed (speed change cycle) as shown in Figure 7 . The additional vehicle operating cost for a speed change cycle of 
each vehicle category can be taken by using the vehicle operating cost tables. Within the selected time slots, additional VOC for each vehicle class can be found for both directions. Now the total additional VOC value per day (due to speed change cycle) for all classes can be estimated. But NZ Transport Agency's Economic Evaluation Manual does not include motorcycles and 3-wheelers, which are widely used in Sri Lanka. VOC for these vehicle types, therefore, are estimated relative to the cost of operating cars, using the factors listed in the Table 2.

\section{Speed change cycle}

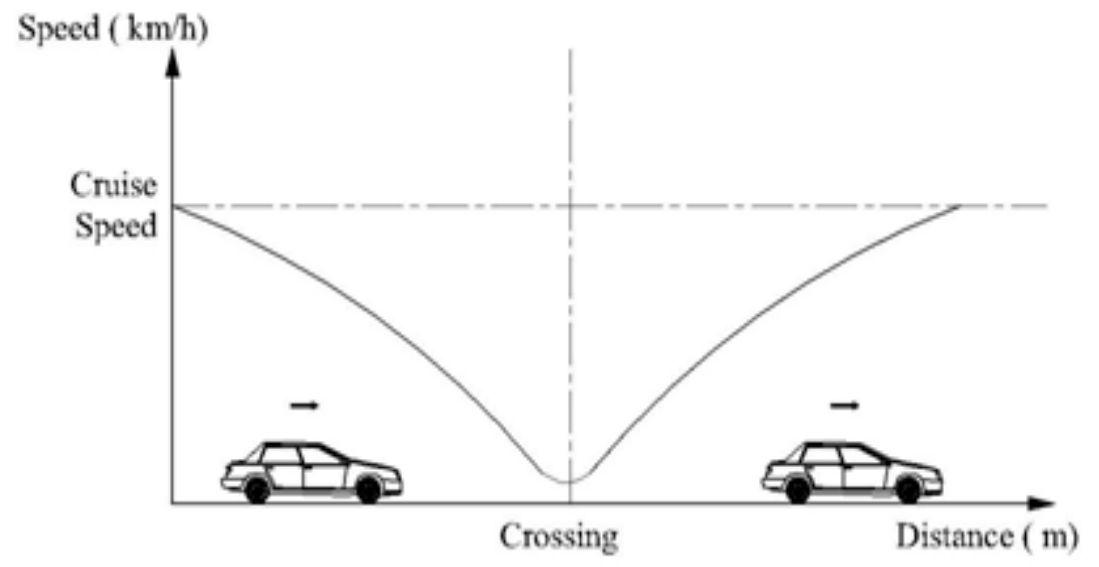

Figure 7. Speed change cycle

Table 2. VOC relative to cost of operating cars

\begin{tabular}{|l|c|c|}
\hline \multicolumn{1}{|c|}{ Cost Category } & Motorcycle & 3- Wheeler \\
\hline Fuel \& Oil & $42 \%$ & $50 \%$ \\
\hline Tyres * & $30 \%$ & $40 \%$ \\
\hline Maintenance \& repairs & $22 \%$ & $35 \%$ \\
\hline Depreciation & $40 \%$ & $70 \%$ \\
\hline
\end{tabular}

$\left({ }^{*}\right.$ Based on difference in wear, in number of tyres, and in tyre costs)

(Source: Assessing public investment in transport sectorDepartment of National planning - Ministry of finance \& planning - Sri Lanka) 
Additional VOC Values are provided by vehicle classes and the vehicle classes are defined as follows.

Table 3. Vehicle classes

\begin{tabular}{|c|c|l|}
\hline 1 & $M C L$ & Motor cycles \\
\hline 2 & $T W L$ & Three wheelers \\
\hline 3 & CAR & Passenger cars \\
\hline 4 & LCV & $\begin{array}{l}\text { Light Commercial Vehicles (Vans, utilities and } \\
\text { trucks up to 3.5 tonnes, gross laden weight. } \\
\text { LCV mainly have single rear tyres but include } \\
\text { some small trucks with dual rear tyres). }\end{array}$ \\
\hline 5 & $M C V$ & $\begin{array}{l}\text { Medium Commercial Vehicles (Two axle heavy } \\
\text { trucks without a trailer, over 3.5 tonnes gross } \\
\text { laden weight). }\end{array}$ \\
\hline 6 & HCV 1 & $\begin{array}{l}\text { Heavy Commercial Vehicles 1 (Rigid trucks with } \\
\text { or without a trailer, or articulated vehicle, with } \\
\text { three or four axles in total). }\end{array}$ \\
\hline 7 & HCV 11 & $\begin{array}{l}\text { Heavy Commercial Vehicles 11 (Trucks and } \\
\text { trailers and articulated vehicles with or without } \\
\text { trailers with five more axles in total). }\end{array}$ \\
\hline 8 & LBU & $\begin{array}{l}\text { Large Passenger Vehicles (Buses, excluding } \\
\text { minibuses). }\end{array}$ \\
\hline
\end{tabular}

Additional VOC for passenger car due to speed change cycle is given in Table 5. For an example, let us consider a passenger car which follows a speed change cycle from an initial cruise speed of $70 \mathrm{~km} / \mathrm{h}$ to a minimum speed of 10 $\mathrm{km} / \mathrm{h}$ before returning to the original cruise speed. Additional VOC is taken as 2.5 (in cents/speed cycle) for the intermediate values of speed change calculated from linear interpolating. Additional VOC due to speed change for each type of vehicles were calculated using vehicle operating cost tables except motorcycles and 3-wheelers which were not given in the NZ Transport Agency's Economic evaluation manual (volume 1). 
Table 4. Passenger car additional VOC due to speed change cycles (cents/speed cycle)



(Source: NZ Transport Agency's Economic evaluation manual, Vol. 1)

Additional VOC for passenger cars could be determined for each time slot as indicated in Table 4. As example, the values for Kaduwela direction are indicated in Table 5.

Table 5. Additional VOC for passenger cars to Kaduwela direction

\begin{tabular}{|c|c|c|c|c|c|}
\hline & To Kaduwela \\
\hline Time & $\begin{array}{c}\text { Initial speed } \\
(\mathrm{km} / \mathrm{h})\end{array}$ & $\begin{array}{c}\text { Final speed } \\
(\mathrm{km} / \mathrm{h})\end{array}$ & CAR & $\begin{array}{c}\text { Additional } \\
\text { VOC due to } \\
\text { speed } \\
\text { change } \\
\text { cycle } \\
\text { (cents/speed } \\
\text { cycle } \text { for } \\
\text { one vehicle }\end{array}$ & $\begin{array}{c}\text { Additional } \\
\text { VOC due } \\
\text { to speed } \\
\text { change } \\
\text { cycle } \\
\text { (cents })\end{array}$ \\
\hline 06:00-08:00 & 46 & 13 & 352 & 1.09 & 383.7 \\
\hline 08:00-09:00 & 48 & 12 & 233 & 1.22 & 284.3 \\
\hline 9:00-12:00 & 51 & 26 & 400 & 0.80 & 320.0 \\
\hline 12:00-14:00 & 49 & 13 & 254 & 1.23 & 312.4 \\
\hline 14:00-16:00 & 51 & 26 & 265 & 0.80 & 212.0 \\
\hline 16:00-18:00 & 48 & 14 & 352 & 1.15 & 404.8 \\
\hline 18:00-22:00 & 54 & 31 & 726 & 0.59 & 428.3 \\
\hline 22:00-06:00 & 61 & 60 & 764 & 0.02 & 15.3 \\
\hline \multicolumn{7}{|c|}{ Total } & & $\mathbf{2 3 6 0 . 8}$ \\
\hline
\end{tabular}


Similarly, additional VOC towards Malabe direction could be also determined and tabulated as above. Then the additional VOC for all vehicle classes, LCV, MCV, HVC I, HCV II and LBU were determined and tabulated separately for both directions. Finally total additional VOC per day for both directions could be summed and tabulated as follows (Table $6)$.

Table 6. Total additional VOC for both directions

\begin{tabular}{|c|r|r|r|}
\hline \multicolumn{4}{|c|}{ Additional VOC due to speed change (cents) } \\
\hline Types of vehicles & To Malabe & To Kaduwela & Sub total \\
\hline MCL & 1546 & 920 & 2466 \\
\hline TWL & 1266 & 752 & 2018 \\
\hline CAR & 3920 & 2361 & 6281 \\
\hline LCV & 4608 & 2853 & 7461 \\
\hline MCV & 4452 & 2818 & 7270 \\
\hline LBU & 5431 & 3431 & 8862 \\
\hline HCV I & 11771 & 7522 & 19293 \\
\hline HCV II & 1349 & 801 & 2150 \\
\hline \multicolumn{4}{|c|}{ Total } \\
\hline
\end{tabular}

The total Additional VOC due to Speed change

$$
\begin{aligned}
\text { in the road section ( per day) }= & 55801 \text { ( NZ cents ) } \\
= & 558.01 \text { ( NZ dollars) } \\
& (1 \mathrm{NZ} \text { dollar }=\text { Rs. 106.2) } \\
= & 558.01 \times 106.2 \\
= & \text { Rs. } \mathbf{5 9 , 2 6 0}
\end{aligned}
$$

\section{Additional travel time}

The speed of traffic is interrupted due to the existing pedestrian crossing and it decelerates to a minimum speed (which may be a complete stop) before accelerating back to its original cruise speed. The additional travel time for a speed change cycle is the difference in travel time for traveling the distance of the speed cycle at the original cruise speed versus through the speed cycle. Table 7 indicates additional travel time (in seconds per speed cycle). Additional travel time for each vehicle class during each time slot was 
also determined by using additional travel timetables and the procedure is similar to how the additional VOC was determined.

Table 7. Total additional travel time for all vehicles categories

\begin{tabular}{|l|r|r|c|c|}
\hline \multicolumn{5}{|c|}{ Additional travel time due to speed change (seconds) } \\
\hline \multirow{2}{*}{$\begin{array}{c}\text { Types of } \\
\text { vehicles }\end{array}$} & To Malabe & To Kaduwela & \multicolumn{2}{c|}{$\begin{array}{c}\text { Total additional travel } \\
\text { time }\end{array}$} \\
\cline { 4 - 5 } & & & (seconds) & (hours) \\
\hline CAR & 52894 & 31716 & 84610 & 23.50 \\
\hline LCV & 22032 & 13219 & 35251 & 9.79 \\
\hline MCV & 8124 & 4912 & 13036 & 3.62 \\
\hline LBU & 4651 & 2799 & 7450 & 2.07 \\
\hline HCV I & 8946 & 5401 & 14347 & 3.99 \\
\hline HCV II & 517 & 291 & 807 & 0.22 \\
\hline
\end{tabular}

\section{Value of time (VOT)}

Travel time is important for vehicle occupants, passenger transport users, pedestrians, cyclists, and freight vehicles etc. The road user values are used to produce travel time values for uncongested and congested traffic conditions. Values of time must be adjusted to reflect the appropriate value for the study year. Since VOT is income based, the most rational index would be based on changes in per capita income. Monthly income by income groups can be obtained from the most recent (e.g. 1996/97) Consumer Finance \& Socioeconomic Surveys conducted by the Central Bank of Sri Lanka.

Table 8. Value of time for all vehicles categories (per one vehicle)

\begin{tabular}{|l|r|r|r|r|}
\hline $\begin{array}{c}\text { Types } \\
\text { of } \\
\text { vehicles }\end{array}$ & $\begin{array}{c}\text { Passengers } \\
\text { per } \\
\text { vehicle }\end{array}$ & $\begin{array}{c}\text { Value of time } \\
\text { (VOT) per one } \\
\text { passenger in } \\
\text { 1999(Rs/hour) }\end{array}$ & $\begin{array}{c}\text { Value of time } \\
\text { (VOT) per } \\
\text { one passenger } \\
\text { in } \\
\text { 2011(Rs/hour) }\end{array}$ & $\begin{array}{c}\text { Value of time } \\
\text { (VOT) per } \\
\text { one vehicle in } \\
\text { 2011(Rs/hour) }\end{array}$ \\
\hline CAR & 2 & 78.62 & 424.39 & 848.78 \\
\hline LCV & 4 & 37.62 & 203.07 & 812.28 \\
\hline MCV & 2 & 23.01 & 124.21 & 248.42 \\
\hline LBU & 60 & 12.41 & 66.99 & 4019.40 \\
\hline HCV I & 2 & 23.01 & 124.21 & 248.42 \\
\hline HCV II & 2 & 23.01 & 124.21 & 248.42 \\
\hline
\end{tabular}


Table 9. Total additional travel time

\begin{tabular}{|l|r|r|r|}
\hline $\begin{array}{c}\text { Types of } \\
\text { vehicles }\end{array}$ & $\begin{array}{c}\text { Total additional } \\
\text { travel time (hours) }\end{array}$ & $\begin{array}{c}\text { Cost for } \\
\text { additional } \\
\text { travel time due } \\
\text { to speed } \\
\text { change per } \\
\text { hour }\end{array}$ & $\begin{array}{c}\text { Total cost for } \\
\text { additional travel } \\
\text { time ( Rs ) }\end{array}$ \\
\hline CAR & 23.50 & 848.78 & $19,948.64$ \\
\hline LCV & 9.79 & 812.28 & $7,953.76$ \\
\hline MCV & 3.62 & 248.42 & 899.56 \\
\hline LBU & 2.07 & $4,019.40$ & $8,317.39$ \\
\hline HCV I & 3.99 & 248.42 & 990.03 \\
\hline HCV II & 0.22 & 248.42 & 55.72 \\
\hline \multicolumn{3}{|c|}{ Total } & \\
\hline
\end{tabular}

Total additional VOC per a typical day for all vehicle classes were computed, as they underwent a speed change cycle due to the existing pedestrian crossing. That amount of Rs. 59,260 is the sum of all breakdown components of VOC which are fuel and oil, tyres, maintenance and repairs, depreciation. The percentage of total base VOC by component for each vehicle type also computed. Therefore total additional cost per day for each component of VOC can be calculated.

At the same time, for the same speed change cycle, additional travel time per day for all vehicle classes was determined. The total cost for additional travel time of all vehicles classes was calculated by considering the annual income of different road users. The total cost time for additional travel time of all vehicle classes per day is Rs. 38, 165.

Since the total cost for additional travel time, the total cost for fuel and oil wastage, total cost for tire wastages, total cost for maintenance and repairs, total cost for depreciation per day is known, by taking in to account of the traffic growth rates and future traffic in Colombo district the total cost saving can be computed. 


\section{Capacity design of overhead bridge}

By considering road capacity for year 2032 (i.e. 20 years from present) it was proposed to improve the road to a reasonable road width consisting of sufficient number of lanes (6) for a desirable level of service. It was also found that a pedestrian crossing of $2 \mathrm{~m}$ width is required to cater to future pedestrian volume in year 2032 as per us highway capacity manual. Hence the overhead pedestrian crossing was designed.

\section{Results and Discussion}

Calculated total cost of the project and cost saving from the new structure is as follows:

\begin{tabular}{|l|l|}
\hline $\begin{array}{l}\text { Total construction cost of } \\
\text { project (as per year of 2012) }\end{array}$ & $=$ Rs. 124, 000,000 \\
\hline $\begin{array}{l}\text { Cost saving from additional } \\
\text { VOC (per day) }\end{array}$ & $=$ Rs. 59,260 \\
\hline $\begin{array}{l}\text { Cost saving from additional } \\
\text { travel time (per day) }\end{array}$ & $=$ Rs. 38,165 \\
\hline $\begin{array}{l}\text { Cost saving per year 1 } \\
\text { (Rs. 59,260 + Rs. 38,165) x 365 }\end{array}$ & $\begin{array}{l}\text { Rs. } 35,560,125 \\
\text { (Rs. 35,560,000) }\end{array}$ \\
\hline
\end{tabular}

Expected Internal Rate of Return of this project is $13.4 \%$ and it should be compared with minimum rate of return in order to make an investment decision. The proposed overhead pedestrian crossing will cost 124 million rupees in 2012 and it is expected to save 35.56 million rupees per year over the next 5 years. By considering the allowable minimum Treasury bill rates of capital which is $12 \%$ and since it is exceeding it, (IRR value 13.4\%) the project seems to be viable.

\section{Conclusions and Recommendations}

It was shown that the best possible way to ensure reduced vehicle operating cost and safe travel along this road stretch for commuters was by constructing a new pedestrian's 
overhead bridge. A complete separation of pedestrian and vehicle movements will be only possible through an overhead pedestrian crossing or an underground pedestrian crossing (pedestrian subway). Although an underground pedestrian crossing (pedestrian subway) is also an option, due to its excessive cost and disturbance to traffic during the construction phase (i.e. when constructing across a road having Average Daily Traffic (ADT) of 39,800) the underground crossing (pedestrian subway) was not considered.

The proposed width of 2 meters of the overhead crossing structure will serve the forecasted pedestrians volume at a reasonable LOS, even after twenty years from now. At present, the capacity of Malabe - Kaduwela road is not adequate, and improvement is needed to overcome the anticipated future traffic congestion along this road section by improving up to 4 lanes. With suggested improvements, initially the LOS of the road will improve considerably, but in twenty years time, it will reach the present level of service of the road if present traffic growth rates persist. As the IRR of this investment exceeds its cost of capital $(10 \%-12 \%)$, the project can be undertaken. This project is considered to be profitable and execution of the project is justified.

\section{References}

The NZ Transport Agency's Economic evaluation manual, volume-1, www.nzta.govt.nz.

Highway Capacity Manual (1985), Special Report 209, Transportation Research Board, National Research Council, Washington, D. C.

Road Development Authority of Sri Lanka (1998), Geometric Design Standards of Roads.

Estimated Mid-year population by Sex and District 20032008 (2010), Department of Census and Statistics, Sri Lanka. 